 \\ International Journal of Social Sciences and Management
}

\section{A Rapid Publishing Journal}

ISSN 2091-2986

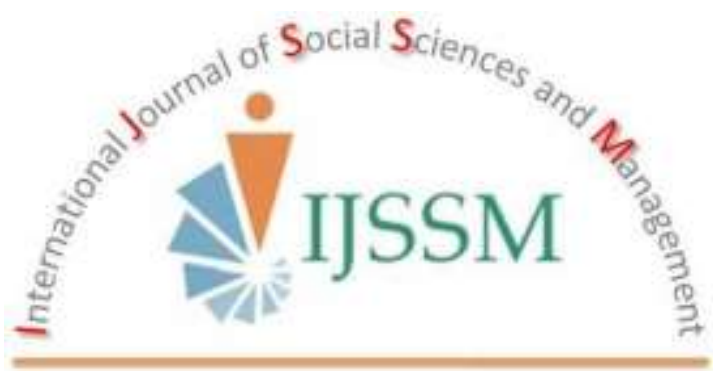

\section{Indexing and Abstracting}

CrossRef, Google Scholar, International Society of Universal Research in Sciences (EyeSource), Journal TOCs, New Jour, Scientific Indexing Services, InfoBase Index, Open Academic Journals Index (OAJI), Scholarsteer, Jour Informatics, Directory of Research Journals Indexing (DRJI), International Society for Research Activity (ISRA): Journal Impact Factor (JIF), Simon Fraser University Library, etc.

Vol-2(1) January, 2015 


\title{
E-GOVERNANCE IN RAJASTHAN STATE UNIVERSITIES: IMPACTS AND IMPEDIMENTS
}

\author{
Shilpa Dhamuniya* \\ Department of Public Administration, University of Rajasthan, Jaipur, India \\ *Email for correspondence: sdhamuniya@gmail.com
}

\begin{abstract}
This research presents the realistic overview of the state of Higher education in one of the largest Indian State, Rajasthan. There are many imperative problems which go back to the princely States, however reorganization of State has uplifted the status of education but the situation still is dismal. The introduction of E-governance by the Government is appreciable for the reason that it shows commitment to bring out fundamental changes in the scenario related to education. The research results are pointing out to definitive policy shifts; to be specific it will be pertinent to draw inferences in entirety.

The scientific research epitomizes the basics that need to be addressed in terms of deconstructing some myths about the policies; constructing some new perceptions about educational institutions and reconstructing new paths to attain the finality of this fundamental objective. The societal transformation will remain unattended unless this sector is strengthened. This study is just a beginning to understand the ground realities and on the basis to visualize the prospective thrust. This particular research has also pointed out some fallacies regarding the tall claims put forth by the government on account of being serious about implementing E-governance but the data collected tells a different story altogether.
\end{abstract}

Key words: E-Governance; E-Learning; Higher Education; E-University

\section{Introduction}

The education system is reflection of development in any society. The values, morality and norms in any social system are determined by the efficacy of its education. Though the hierarchy in educational system is important in the larger sense of its applicability but the role of higher education is more prudent in the entire spectrum of education. This study in particular focuses on the domain of higher education in the largest state of India, Rajasthan (Dhamuniya et al., 2012). The economic growth rate in Rajasthan is satisfactory but many areas still need to be relooked in terms of delivering the social justice to common person. The social justice cannot be ensured unless people are educated and they contribute to the call of economic growth. The onus of socio-economic balance lies on the institutions of higher education in particular as these are the institutions of research and dissemination of knowledge. A knowledge based society can be created amongst many parameters by providing accessibility to education to every individual (Riley, 2000). Therefore it is presumed that an educated citizenry will contribute in the building of society which carries the legacy of just society forward. The inherent anomalies can be taken care of by advancement of higher education by empowering these institutions in fundamental development (De', 2005).

The importance of higher education cannot be belittled. To understand and explore the inbuilt hindrances this research provides basic input to relook at the educational Policy (Heeks, 2001). It is based on the analysis of primary data collected by Researcher through questionnaire and interview as the tools of data collection. Additionally the Researcher also sought the information under RTI Act. The data collected has been subjected to PASW statistical software of IBM to find out the covariance amongst different variables. The respondents constituted three categories viz., Teaching; Non-teaching and students including Researchers from two types of UniversitiesTechnical and Non-technical. Despite the best efforts by researcher the response was not as expected from institutions of higher education. This apathy is alarming and as student of Public Administration it is imperative to search for the right answers to help policy makers to focus on the right issues. The lapses in the policy formulation or implementation need to be addressed properly. 
E-governance or 'Electronic Governance' is basically the application of Information and Communications Technology to the processes of Government functioning in order to bring about 'Simple, Moral, Accountable, Responsive and Transparent' (SMART) governance (Gupta and Bagga, 2008). Dr. APJ Abdul Kalam, former President of India, has visualized E-governance in the Indian context to mean: "A transparent smart E-governance with seamless access, secure and authentic flow of information crossing the interdepartmental barrier and providing a fair and unbiased service to the citizen" (Second ARC-11th Report, 2005).

\section{Objectives of the Research}

- To study the status of E-governance in Higher Education.

- To understand the impacts and impediments of applying E-governance in Technical and NonTechnical Universities.

- To assess the comparative trends in Technical and Non-Technical Universities so that it can provide research inputs for making a more pragmatic education policies in the sector of Higher Education.

- To understand how E-governance can become a productive tool for improving the environment of Higher Education.

- To uphold morality and ethics in this sector which is essential for sensitizing all functionaries of Higher Education towards humanness?

- To find out Regresses which can help government to establish Universities with more international standard?

\section{A Rational of the Study}

- No such study has been done earlier in the Rajasthan to study the role of E-governance in higher education sector, so this will be the first study in the field of E-governance in relation to higher education.

- At present E-governance is foremost need of every organization and India is no exception to this, therefore India is also spearheading towards econnectivity since last few years. However, the education sector is so far from this connectivity. The study basically epitomizes the interplay of various components of E-governance on education sector.

- India's higher education system is the third largest in the world, after China and the United States. The study results will uncover the present scenario of the State's higher education system and give suggestions to improve e-connectivity in governance. This study will be a unique collection in Educational Research and help in policy making.

\section{Independent Variables}

1. Education

2. Ethics

3. Economy

4. Efficiency

\section{Dependent Variables}

1. E-governance

\section{Research Hypotheses}

1. There is a relationship between all variables i.e. E-governance, Education, Economy, Efficiency and Ethics amongst all functionaries (Teaching, Non -teaching, Student) in Technical Universities.

2. There are significant variances in Education, Economy, Efficiency, and Ethics in Technical Universities due to application of E-Governance in Rajasthan.

3. There is a relationship between all variables i.e. Egovernance, Education, Economy, Efficiency and Ethics amongst all functionaries (Teaching, Non teaching, Student) in Non-Technical Universities.

4. There are significant variances in Education, Economy, Efficiency and Ethics in Non-Technical Universities due to application of E-Governance in Rajasthan.

Rajasthan, "Royal land of India", famous among tourists from across the globe, has taken several initiatives to improve the educational scenario in the state. As per the recent census done in 2001, the state has recorded literacy rate of $61.03 \%$, which is $22.48 \%$ higher than previous census in 1991. State has listed itself at seventh position among states and Union Territories of the country. Literacy among females has also increased from 20.44 to $44.34 \%$ during the decade. 'Decade Literacy Award' and 'Decade Female Literacy Award' were given to the state on National Literacy Day. "Sarva Siksha Abhiyan" is used as a tool to universalize the elementary education in the state. Apart from school education, various initiatives have also been taken to enhance the status of higher education. Currently Rajasthan has 12 Universities, 4 Deemed Universities, 117 Government Colleges, 751 Private Colleges \& 9 Self Financing Colleges. Most of the Universities are members of the Association of Indian Universities. Some of them are the state universities, while others are the deemed Universities.

With the collective efforts of University Grants Commission, Ministry of Human Resource Development, Govt. of India and the Department of Higher Education, Govt. of Rajasthan, the State is blessed with 15 Universities and 8 Deemed Universities catering to the educational 
needs of the state by imparting higher education under different categories. (Dept. of college Edu., 2013).

This study has comprehensively presented the overview of the existent system of Universities in Rajasthan. Interestingly the researcher contacted the respective Universities through RTI Act to find out the progress of each University in respect of the application of Egovernance. Except for Maharana Pratap University of Agriculture and Technology, Udaipur and Swami Keshwananda Rajasthan Agriculture University, Bikaner where some headway has been made in this regards, most of the others have yet to fulfill the objectives of Egovernance.

The scientific research epitomizes the basics that need to be addressed in terms of deconstructing some myths about the policies; constructing some new perceptions about educational institutions and reconstructing new paths to attain the finality of this fundamental objective. The societal transformation will remain unattended unless this sector is strengthened. This research study is just a beginning to understand the ground realities and on the basis to visualize the prospective thrust. The concept of E-governance is now not new but the application is still in the initial stage. This particular research has also pointed out some fallacies regarding the tall claims put forth by the government on account of being serious about implementing E-governance but the data collected tells a different story altogether. The limited responses also are a matter of great concern as it reflects our conventional mindsets which are prevalent in modern era. There are many institutions which are progressive, the reference of which is already been made in previous chapters but the overall picture is bleak. The Rajasthan which is fast growing economy has to use the potential to optimize the effects of technological advancement. The educational sector has an additional edge over other sectors in its being the instrument of transformation. This sector is also significant as skill improvisation is attainable through this sector which consequentially is primary human resource for any secondary sector.

\section{Major Inferences- A Recapitulation}

\section{A. Statistical Results}

The comparative statistics of two types of Universities in Rajasthan points out very significant trends. All variables selected for this research study proves have significant correlation and regression seems to be in the expected direction. However the variation in the medium value shows some difference. In TU the values are higher between Economy and E-governance than in NTU where the values are higher between Ethics and E-governance. The underpinning reasons seem to be plausible, for technical system economy is at the forefront and in non-technical ethics is a more obvious one to be on surface. The regression equation in both types also explains that all Regression Coefficient are individually significant for the present research study.

\section{B. Two-Ended Inferences}

The above results are based on computing Spearman Coefficient and Linear Regression Coefficient (Table 1 and Table 2). "The DV refers to the status of the 'effect' or 'outcome' in which the researcher is interested; the Independent Variable refers to the status of the presumed 'cause' changes which lead to changes in the status of the Dependent Variable... any event or condition can be conceptualized as either an independent or a dependent variable"(Rosenthal \& Rosnow et al., 1991). To find out the variations the special sets of questionnaire consisting of two-ended questions was instituted. A concise interpretation of which is as follows:

$>$ The two-ended set of questionnaire when instituted to both types, there emerged a vast difference in responses. For instance when asked for the institutional support for online interactions TU respondents were in the favor of this whereas NTU respondents were negative on this. Again the reason for this variation is inherent in the nature of the kind of system. Even the similar difference is registered in the having access to the online notifications from the respective institutions. Also when the questioned about video-conferencing the response was on the expected lines. This explains that the importance of e- Governance has been accepted invariably by all sections of the people across the universities and the variations in both types of categories are manifested in our research study.

$>$ In the response to the category of non-teaching at least two questions have registered a vast variation, one when they were asked regarding the facility of e-exchange from other sections TU again responded in the favor of this where as NTU was found to be in negation for this question; two when queried regarding online information sharing with students a similar variation was observed. This supports the argument that those institutions which have initially imbibed the technical mindsets mostly believe in promoting econnectivity with all sections.

$>$ The response from the largest users of these institutions i.e. students have participated more genuinely and mirroring the actual situation most of the results reflected that they have not been given the technical support which is often claimed by the Universities in both the categories. The vast variation amongst the categories has been registered in one question which was regarding the web-portal of government for research content. The TU students responded in favor while the students of NTU were not in favor of this. 
Table 1: Spearman's Coefficient of Correlations (Technical Universities)

Correlations

\begin{tabular}{|c|c|c|c|c|c|c|c|}
\hline & & & Education & Efficiency & Economy & Ethics & Egovernance \\
\hline \multirow[t]{15}{*}{ Spearman's rho } & \multirow[t]{3}{*}{ Education } & Correlation Coefficient & 1.000 & $.640^{x x}$ & $.606^{\mathrm{kx}}$ & $.411^{\pi x}$ & $.494^{\pi x}$ \\
\hline & & Sig. (2-tailed) & & .000 & .000 & .000 & .000 \\
\hline & & $N$ & 120 & 120 & 120 & 120 & 120 \\
\hline & \multirow[t]{3}{*}{ Efficiency } & Correlation Coefficient & $640^{\pi x}$ & 1.000 & $.712^{\mathrm{xx}}$ & $.664^{x \pi}$ & $.736^{x \times}$ \\
\hline & & Sig. (2-tailed) & .000 & & .000 & .000 & .000 \\
\hline & & $N$ & 120 & 120 & 120 & 120 & 120 \\
\hline & \multirow[t]{3}{*}{ Economy } & Correlation Coefficient & $606^{\mathrm{sx}}$ & $.712^{2 x}$ & 1.000 & $.594^{\pi x}$ & $.654^{x x}$ \\
\hline & & Sig. (2-tailed) & .000 & .000 & . & .000 & .000 \\
\hline & & N & 120 & 120 & 120 & 120 & 120 \\
\hline & \multirow[t]{3}{*}{ Ethics } & Correlation Coefficient & $.411^{\pi \pi}$ & $.664^{2 \pi}$ & $.594^{x \pi}$ & 1.000 & $.609^{x x}$ \\
\hline & & Sig. (2-tailed) & .000 & .000 & .000 & & .000 \\
\hline & & N & 120 & 120 & 120 & 120 & 120 \\
\hline & \multirow[t]{3}{*}{ Egovernance } & Correlation Coefficient & $.494^{\pi / 2}$ & $.736^{x \pi}$ & $.654^{2 \pi x}$ & $609^{x x}$ & 1.000 \\
\hline & & Sig. (2-tailed) & .000 & .000 & .000 & .000 & \\
\hline & & $N$ & 120 & 120 & 120 & 120 & 120 \\
\hline
\end{tabular}

*. Correlation is significant at the 0.01 level (2-tailed).

Table 2: Spearman's Coefficient of Correlations (Non-Technical Universities)

Correlations

\begin{tabular}{|c|c|c|c|c|c|c|c|}
\hline & & & Education & Efficiency & Economy & Ethics & Egovernance \\
\hline \multirow[t]{15}{*}{ Spearman's rho } & \multirow[t]{3}{*}{ Education } & Correlation Coefficient & 1.000 & $649^{x x}$ & $.508^{\mathrm{Rx}}$ & $.423^{3 \pi}$ & $.588^{\pi x}$ \\
\hline & & Sig. (2-tailed) & & .000 & .000 & .000 & .000 \\
\hline & & N & 182 & 182 & 182 & 182 & 182 \\
\hline & \multirow[t]{3}{*}{ Efficiency } & Correlation Coefficient & $649^{x x}$ & 1.000 & $.643^{2 x}$ & $.658^{\mathrm{xx}}$ & $.875^{2 x x}$ \\
\hline & & Sig. (2-tailed) & .000 & & .000 & .000 & .000 \\
\hline & & N & 182 & 182 & 182 & 182 & 182 \\
\hline & \multirow[t]{3}{*}{ Economy } & Correlation Coefficient & $.508^{x x}$ & $.643^{2 x}$ & 1.000 & $.616^{\mathrm{nx}}$ & $.685^{\mathrm{kn}}$ \\
\hline & & Sig (2-tailed) & .000 & .000 & & .000 & .000 \\
\hline & & N & 182 & 182 & 182 & 182 & 182 \\
\hline & \multirow[t]{3}{*}{ Ethics } & Correlation Coefficient & $423^{2 x}$ & $.658^{x x}$ & $.616^{\text {sx }}$ & 1.000 & $.742^{\mathrm{sx}}$ \\
\hline & & Sig. (2-tailed) & .000 & .000 & .000 & & .000 \\
\hline & & N & 182 & 182 & 182 & 182 & 182 \\
\hline & \multirow[t]{3}{*}{ Egovernance } & Correlation Coefficient & $.588^{x x}$ & $.875^{2 x}$ & $.685^{2 \pi}$ & $.742^{\mathrm{xx}}$ & 1.000 \\
\hline & & Sig. (2-tailed) & .000 & .000 & .000 & .000 & \\
\hline & & N & 182 & 182 & 182 & 182 & 182 \\
\hline
\end{tabular}

*. Correlation is significant at the 0.01 level (2-tailed). 


\section{Policy Trajectory}

As the student of Public Administration policy making is a fundamental stream. This research study has unfolded many realities and results which are equally fascinating when subjected to the statistics. The e- Governance is the most common phrase but least practiced. The pertinent question is how to change the mindsets of people when those who are responsible to bring out such change are themselves not willing to do. The Universities are not only the responsible for imparting knowledge which has now become easily accessible to everyone but are responsible for carrying out the socially relevant researches. The core focus therefore remains on replacing the conventionality of approach with the technologically driven approach.

The policy process is a serious exercise and need to take into account all factors; this becomes more important when a vibrant sector is involved. The summary of results has been presented earlier. This particular discussion centers around the fact that how to resolve anomalies within and outside the system through policy interventions.

The policy makers must focus on the following dimensions collectively. The results show a concern for change which is inevitable. This concern has been put diagrammatically below by researcher in the subsequent pages. For the benefit of the larger readers and prospective researchers a comparative slides have been presented to gather the gist of the entire research.

$\checkmark \quad$ The policy makers must be ready to accept the need for policy shift from traditional to technological. Also in this is inherent the need to formulate the precise policies, the more precision a policy has more easy it becomes to implement.

$\checkmark \quad$ The exhaustive drive is expected from the policy makers to initiate total digitalization of its documents to be posted on the respective University websites. The transparency which has morality inbuilt has to be ensured that correct information is uploaded.

$\checkmark \quad$ The rules and regulations including the amended rules must be put on the screen. The language and translation facilities regarding rule framing is very important aspect. Thus the ambiguity of language must be taken into consideration.

$\checkmark$ The research projects/ financial status/ examinations/ grievance removal/ minutes of committees/ decisions and such other general information must be provided on the website and e-interaction must be facilitated.

$\checkmark$ The twenty four hours services like many professional institutions provide to promote active participation and exploration of areas of research must be extended. $\checkmark$ The webinars have come up as an important mechanism to connect with the Professionals anywhere in the slotted hours and it is high time that Rajasthan respond to this need immediately in the domains of higher education.

$\checkmark$ The schemes to empower students must be provided by the university systems. The employment news must also be posted on the websites in addition to the other basic information.

$\checkmark \quad$ The automated system of delivering lectures has to be promoted.

The policy making is a continuous process and time frames itself are decisive in ensuring any change. The onus of change also lies on implementing authorities which for this purpose include individuals at all levels of functionaries. The path is clear and change is expected the need is to make prudent policies.

\section{Acknowledgement}

This work was supported by the University Grant Commission, India under grant Junior Research Fellowship.

\section{References}

De' R (2005) Assessment of e-government projects - a case study of Bhoomi, India. In: Marshall S, Taylor $\mathrm{W}$ and $\mathrm{Yu} \mathrm{X}$ (eds.). Encyclopedia of Developing Regional Communities with Information and Communication Technology. Idea Group Reference, London. ISBN: 1591405750

Department of College Education, Government of Rajasthan, (29Nov.2013). Retrieved from http://collegeeducation.rajasthan.gov.in/httpdocs/eprc.ht $\mathrm{m}$

Dhamuniya S (2012) E-governance in The Domain of Higher Education: A Comparative study of State Technical and Non-Technical Universities in Rajasthan (Doctoral thesis), Department of Public Administration, University of Rajasthan, Jaipur

Gupta P and Bagga RK. (2008) Compendium of e-governance initiatives in India. Universities Press, Delhi.

Heeks RB (2001) Building e-Governance for Development, iGovernment paper no.12, IDPM, University of Manchester, UK.

Riley TB. (2000) Electronic governance and electronic democracy: living and working in the wired world. London: Commonwealth Secretariat

Rosenthal R and Rosnow RL (1991) Essentials of behavioral research: Methods and data analysis (2nd eds). New York: McGraw-Hill.

Second ARC-1 th $^{\text {th }}$ Report (2005) Promoting E-governance, Chapt.-2, p-8, Retrieved from http://arc.gov.in/11threp/ARC_11threport_Ch2.pdf 